\title{
Measuring the stability of individual growth patterns
}

\author{
H. GOLDSTEIN \\ Institute of Education, University of London \\ Received 14 January 1981; revised 11 June 1981
}

\begin{abstract}
Summary. Two measures of stability based on longitudinal growth data are described. One, termed a growth constancy index, is based on the variation of each individual's (standardized) measurement about his or her average. The other, called a growth separation index, measures the extent to which individual growth curves cross each other. The uses of these indices are described and formulae for calculating then and their standard errors are given. They are applied to an example involving group comparisons of height, weight and skinfold data.
\end{abstract}

\section{Introduction}

Given serial measurements on a sample of individuals, it is sometimes useful to quantify the degree of 'stability' exhibited by each individual's set of measurements. Thus, in figure 1, height measurements for three individual boys are plotted on British growth charts (Tanner et al. 1966) for five yearly ages from 5-0 to 9.0 years. Individual 1 keeps closely to his average percentile, individual 2 varies somewhat haphazardly about his average percentile and individual 3 has a higher than average growth velocity followed by a less than average velocity. If the measurements were six-monthly, an individual with a relatively large variation in height might be an example of someone subject to considerable seasonal effects; an individual with large variation in weight of someone subject to large alterations in nutritional intake. Thus a measure of growth variability may be important in helping to distinguish individuals or groups. Another feature of these curves is that they do not cross, so that although growth is not very stable for individuals 2 and 3 , all the growth curves are well separated, with the rank order of measurements remaining the same from occasion to occasion. In a random sample of individuals, an individual whose growth curve crosses a relatively large proportion of those for other individuals can be said to exhibit a growth pattern out of line with those of most other individuals.

This leads us to consider two measures or indices of stability and call them 'growth constancy' and 'growth separation'. They have also been referred to as growth 'tracking' indices (Foulkes and Davies 1981, McMahan 1981). The examples in this paper use body measurements on children, but in principle the indices are applicable to other kinds of longitudinal data such as mental test scores. In such cases, however, especially where different measuring instruments are used on different occasions, the substantive interpretation of the indices may not be quite so straightforward (see Goldstein 1979; chapter 3).

\section{Methods}

Growth constancy index

The first step in deriving this index is to standardize the measurements at each occasion to yield distributions with equal means and standard deviations. (For the case of unstandardized measurements see McMahan 1981). In the case of pre-adolescent height, for example, which has a symmetric and near-gaussian distribution, a simple 


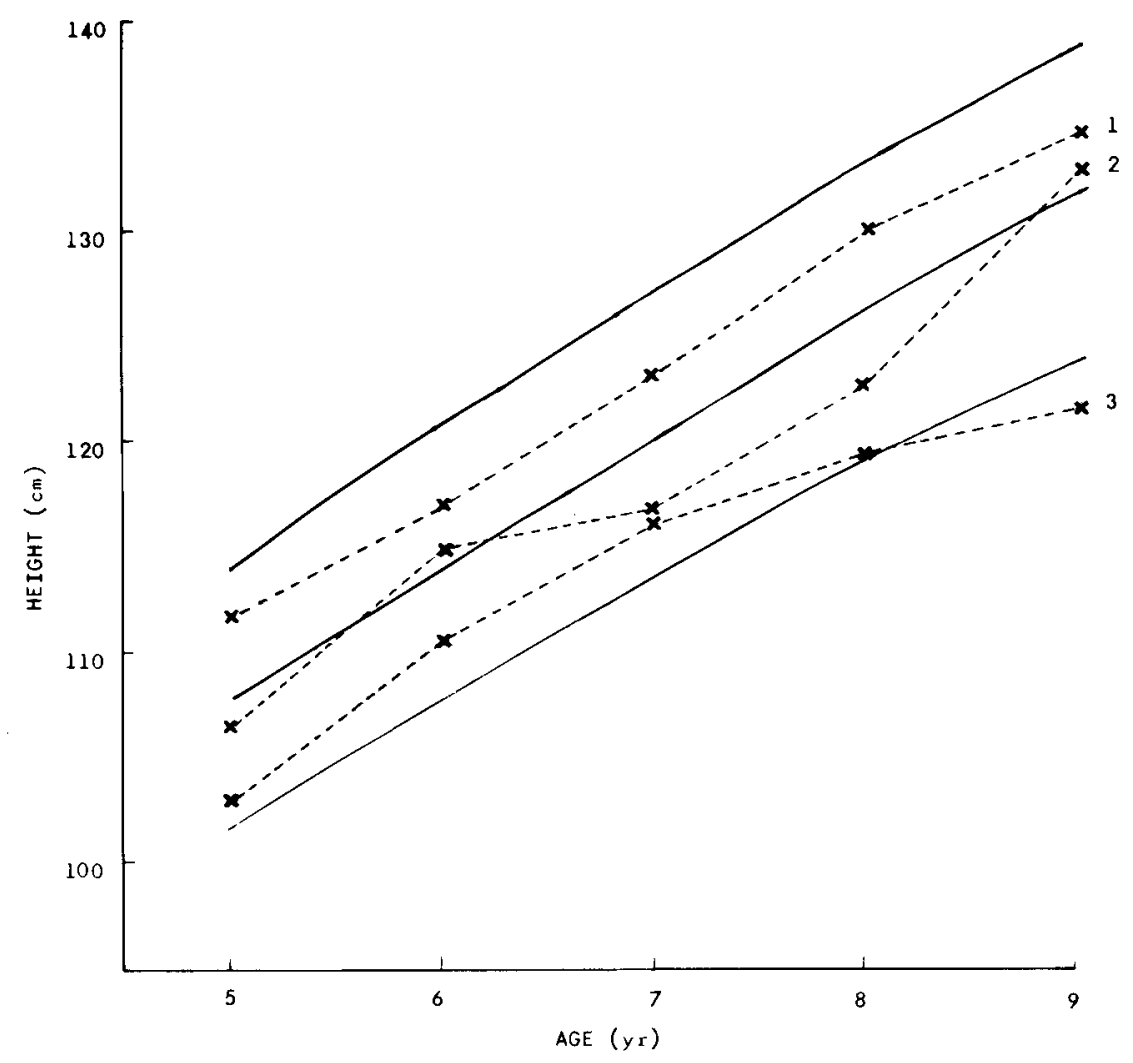

Figure 1. Heights of three boys plotted on British Growth Chart.

transformation will give a mean of zero and a standard deviation of one at each age. Otherwise, the values from the available (random) sample may be used empirically to produce identical distributions based on observed rankings. Strictly speaking, however, since it is only the relative variabilities which are compared using this index, completely identical distributions are not required. We assume that each individual is measured at the same finite number of occasions. For some age ranges, for example during adolescence, biologically based scales such as skeletal age might be preferable, or ages can be measured from a convenient origin such as the age at peak height velocity.

For each individual we have a measurement, $x_{i j}$, at each of $p$ occasions, where $i$ refers to the individual and $j$ to the occasion. We obtain a measurement of variation of these measurements for each individual by forming

$$
\begin{aligned}
S_{i}^{2} & =\sum_{j=1}^{p}\left(x_{i j}-\bar{x}_{i}\right)^{2} \\
\bar{x}_{i} & =\frac{1}{p} \sum_{j=1}^{p} x_{i j}
\end{aligned}
$$


and defining, for a sample size $n$

$$
D=1-\frac{1}{(n-1) p} \sum_{i=1}^{n} S_{i}^{2} .
$$

Thus $D$ is the proportion of the total variation $p(n-1)$ not attributable to individuals' variations about their mean (standardized) measurement. The individual values $S_{i}^{2}$ are relative measures of each individual's constancy, allowing us to compare individuals or groups of individuals. There is, clearly, a complete absence of constancy when all the occasion-to-occasion correlations are zero, when we have

$$
D=1 / p \text {. }
$$

Hence we can define a modified index (appropriate in the usual case when all correlations are non-negative).

$$
\begin{aligned}
C & =\frac{D-1 / p}{1-1 / p} \\
& =1-\frac{1}{(n-1)(p-1)} \sum_{1}^{n} S_{i}^{2}=\bar{r}
\end{aligned}
$$

where $\bar{r}$ is the average of the $\frac{1}{2} p(p-1)$ occasion-to-occasion intercorrelations. For some measurements, for example behavioural or biochemical ones, we may choose to regard some of the growth variation as due to 'measurement error' and would not wish to include this in the index. In such cases we can 'disattenuate' the intercorrelations by subtracting known or estimated measurement error variances from the betweenindividual variances. An alternative approach is to fit a low-order polynomial (or other) growth curve, for example a quadratic, to each individual's measurements and then to use the values at each occasion predicted by these curves rather than the observed values. The choice of growth curve, and in particular the order of polynomial, is important since this will effectively define the measurement error variance, and it seems difficult to provide general guidelines. The relevant theory is given by McMahan (1981). For most body measurement data the measurement error variances are small enough to be ignored.

\section{Growth separation index}

This index measures the extent to which individual growth curves cross each other. We count the number of times $\left(m_{i}\right)$ the line (growth curve) joining the $p$ measurements of the $i$ th individual intersects at least once with the lines of other individuals over the $p$ occasions. Define, for a sample size $n$,

$$
R=1-\frac{1}{n(n-1)} \sum_{i=1}^{n} m_{i} .
$$

$R$ is the proportion of pairs which do not cross and clearly is a measure of separation, being zero when the maximum possible crossings occur and one when no crossings occur. When the correlation between occasions is zero, the probability of a pair of random lines not crossing is $\frac{1}{2}$ and for $p$ occasions the probability of a pair of random growth curves (formed by joining successive measurements by straight lines) not crossing is $1 /\left(2^{p}-1\right)$.

The values $m_{i}$ are relative measurements of separation for each individual and can be used to compare individuals. As before, we can allow for measurement error, where 
appropriate, although in this case it seems we can only adopt the approach of fitting low-order growth curves and counting the number of crossings of these curves. (Foulkes and Davies (1981) give details.) For body measurements such as height, where we wish to summarize growth by fitting, say, low-order polynomials, we might also wish to use these in order to calculate a separation index. In general the value of the index will decrease, the higher the order of the polynomial.

\section{Estimation of standard errors}

Exact expressions for estimates of the standard errors of the two indices are difficult to obtain. Nevertheless, the estimators are of a form which allows us to use the technique of 'jacknifing' (Miller 1974). These jacknife estimates are obtained as follows. Let $\breve{\theta}_{i}=n \breve{\theta}-(n-1) \breve{\theta}_{-1}$. Then the jacknife estimate of $\theta$ is

$$
\hat{\hat{\theta}}=\frac{1}{n} \sum \hat{\theta}_{i}
$$

This estimator has the property that any bias in $\hat{\theta}$ is reduced, and it has an estimated standard error

$$
\left[\frac{1}{n(n-1)} \sum(\hat{\theta}-\hat{\hat{\theta}})^{2}\right]^{1 / 2} .
$$

Hence we can use (4) and (5) to construct confidence intervals.

\section{Results}

\section{Example}

The data are measurements of height, weight and triceps skinfold made on a sample of 62 children from the London Growth Study (Tanner et al. 1966) who had a complete set of these measurements at ages 5, 6, 7, 8 and 9 years. The measurements were transformed to have zero means and unit standard deviations at each age. As with most growth curve models, both the indices described above assume that for each individual the measurements are all made at the same set of ages. In practice, however, children arrive earlier, or more generally later, than the 'target' age, which for the London Growth Study is their birthday. In some cases this discrepancy is large, and to overcome this difficulty, all measurements have been 'adjusted' to the target ages using local quadratic or linear interpolation. The method is described in Goldstein (1979) with a more detailed discussion in Goldstein (1981).

Figures 2 and 3 show, for height, the cumulative probability plots for the constancy and separation indices $S_{i}^{2}$ and $m_{i}$ respectively, using the standardized values $\left\{1-S_{i}^{2} /(p-1)\right\}$ and $\left\{1-m_{i} /(n-1)\right\}$. These allow us to select 'atypical' individuals, for example those beyond the $3 \mathrm{rd}$ or 97 th percentiles. Figures 4 and 5 show three individuals plotted against the British growth standards, one at about the $3 \mathrm{rd}$, one at about the 50th and one at about the 97th percentile on each index.

Table 1 shows the constancy index value for the three measurements, together with jacknife estimates of the indices and their standard errors. The overall and jacknife estimates agree very closely and the standard errors are relatively small. Both height and weight have high coefficients with skinfold rather lower.

Table 2 gives the corresponding separation index estimates showing a similar pattern, but overall rather lower values. Table 3 shows how the separation index decreases the higher the degree of growth curve fitted, which is what one would expect 


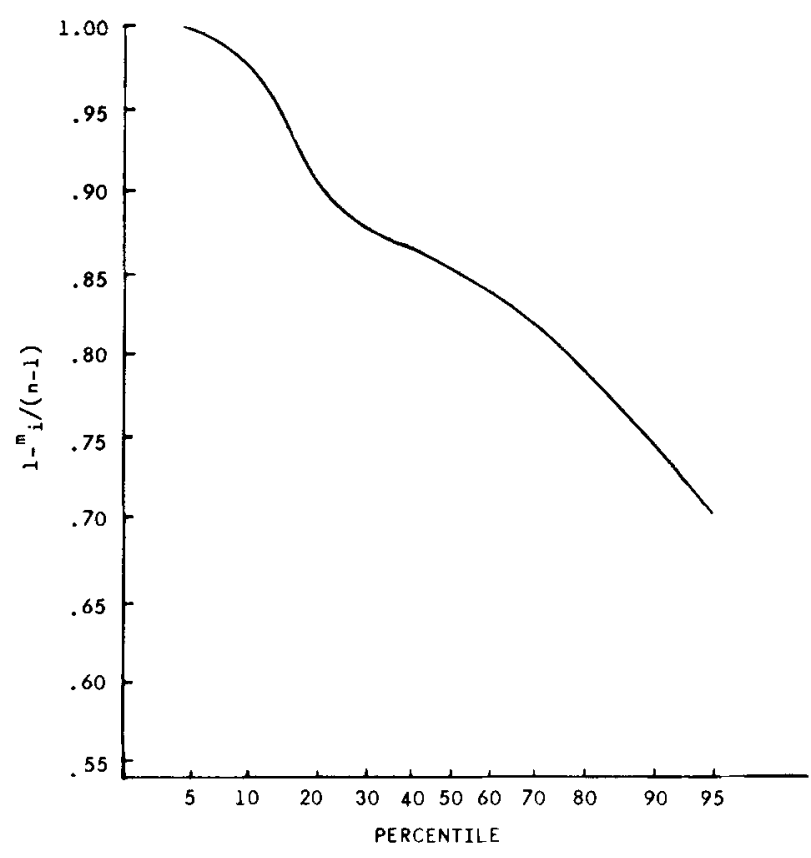

Figure 2. Cumulative probability plot for constancy index.

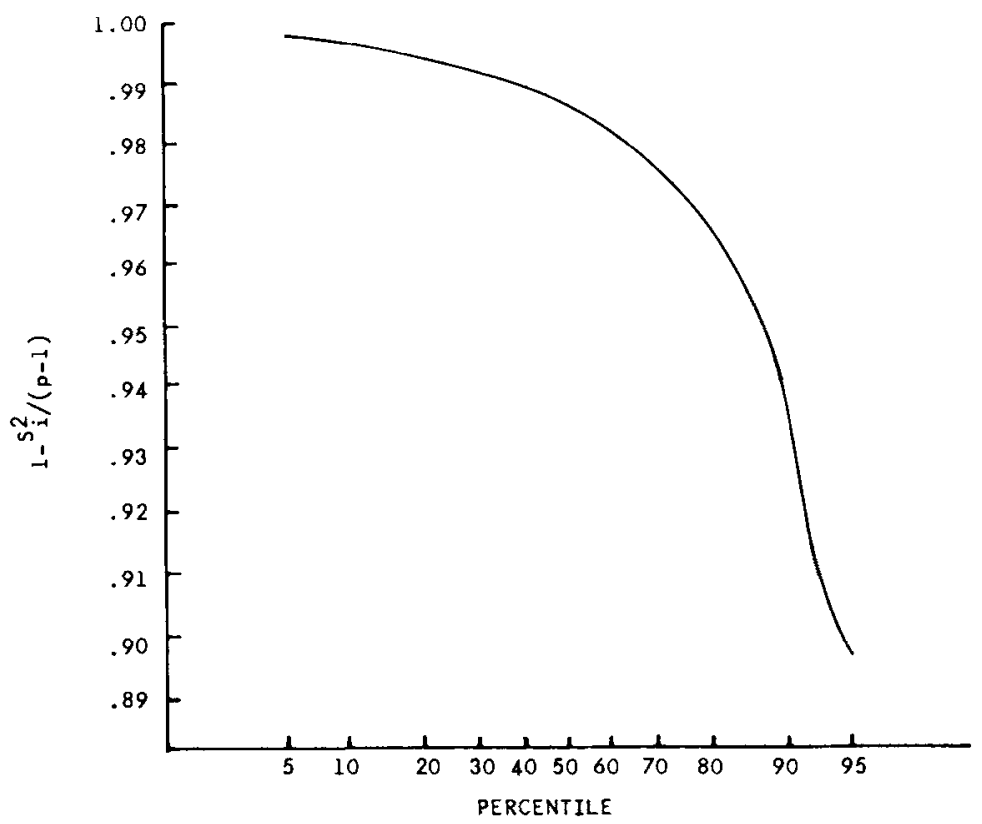

Figure 3. Cumulative probability plot for separation index. 


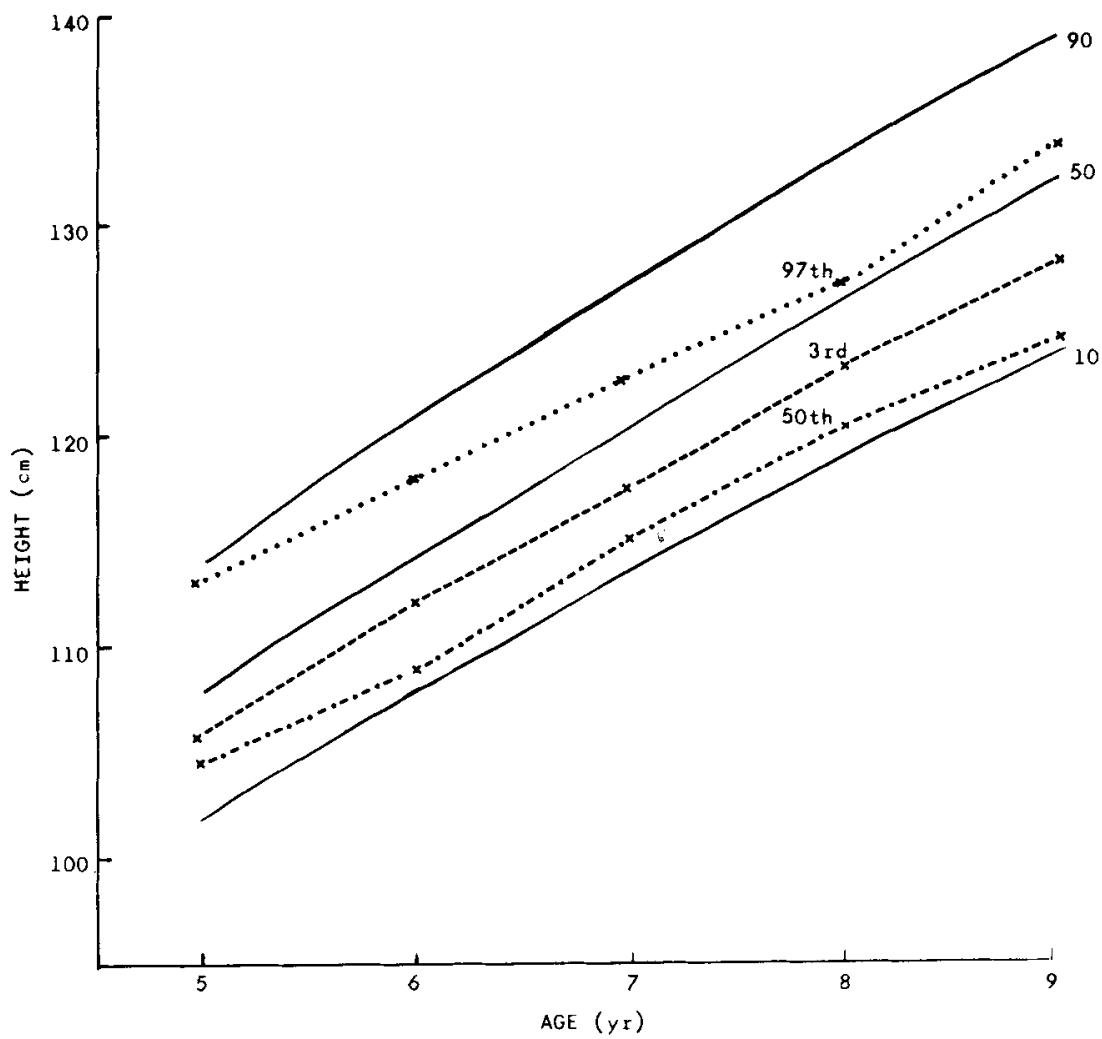

Figure 4. Heights of three boys who are at approximately 3 rd, 50th, 97th percentiles of constancy index, plotted on British Growth Chart.

Table 1. Constancy index estimates.

\begin{tabular}{lccc}
\hline Measurement & $\begin{array}{c}\text { Overall } \\
\text { estimate }\end{array}$ & $\begin{array}{c}\text { Jacknife } \\
\text { estimate }\end{array}$ & $\begin{array}{c}\text { Standard } \\
\text { error }\end{array}$ \\
\hline Height & 0.97 & 0.97 & 0.004 \\
Weight & 0.95 & 0.95 & 0.008 \\
Skinfold & 0.75 & 0.76 & 0.040 \\
\hline
\end{tabular}

Table 2. Separation index estimates.

\begin{tabular}{lccc}
\hline Measurement & $\begin{array}{c}\text { Overall } \\
\text { estimate }\end{array}$ & $\begin{array}{c}\text { Jacknife } \\
\text { estimate }\end{array}$ & $\begin{array}{c}\text { Standard } \\
\text { error }\end{array}$ \\
\hline Height & 0.85 & 0.85 & 0.02 \\
Weight & 0.82 & 0.82 & 0.02 \\
Skinfold & 0.58 & 0.56 & 0.04 \\
\hline
\end{tabular}




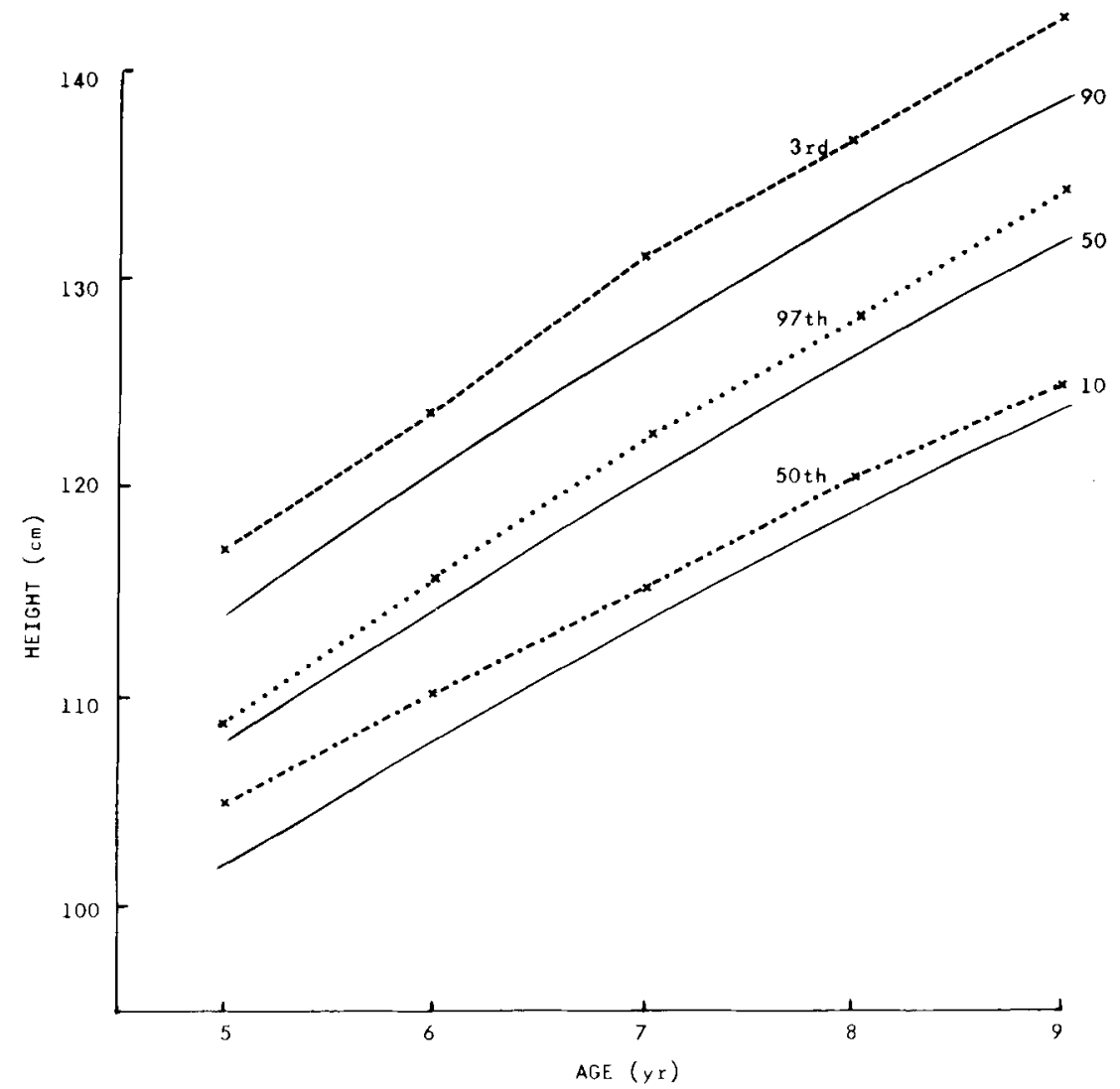

Figure 5. Heights of three boys who are at approximately $3 \mathrm{rd}, 50 \mathrm{th}, 97$ th percentile of separation index, plotted on British Growth Chart.

Table 3. Separation index estimates for straight line and quadratic fitted growth curves and intercorrelations of estimates.

\begin{tabular}{lcc}
\hline Measurement & Straight line & Quadratic \\
\hline Height & 0.88 & 0.86 \\
Weight & 0.86 & 0.85 \\
Skinfold & 0.70 & 0.64 \\
\hline Intercorrelations & & \\
1. Height & Quadratic & All occasions \\
$\quad$ Straight line & 0.93 & 0.92 \\
$\quad$ Quadratic & & 0.97 \\
2. Weight & Quadratic & All occasions \\
$\quad$ Straight line & 0.81 & 0.78 \\
$\quad$ Quadratic & & 0.94 \\
3. Skinfold & Quadratic & All occasions \\
Straight line & 0.83 & 0.73 \\
$\quad$ Quadratic & & 0.89
\end{tabular}

'All occasions' is approximately equivalent to filting a fourth-degree polynomial. 
as a result of the degree of 'smoothing' performed by low-order polynomial growth curves. The correlations between the indices for different-degree curves is fairly high for height but less so for weight and skinfold. This is presumably a reflection of the more linear growth in height at these ages than in the other two measurements.

Table 4 shows the low correlations using individual measurements between the two indices, which is actually zero for skinfold, and there is no non-linear relationship either. This underlines the fact that different aspects of the growth patterns are being measured.

Table 5 shows the separate results for boys and girls. The estimates are very similar and none of the differences is significant.

Table 4. Correlations between separation (all occasions) index and constancy index.

\begin{tabular}{lc}
\hline Measurement & Correlation \\
\hline Height & $0 \cdot 33$ \\
Weight & $0 \cdot 39$ \\
Skinfold & $0 \cdot 00$ \\
\hline
\end{tabular}

Table 5. Jacknife estimates of constancy and separation indices for boys and girls (standard errors in brackets).

\begin{tabular}{|c|c|c|c|c|}
\hline \multirow[b]{2}{*}{ Measurement } & \multicolumn{2}{|c|}{ Boys } & \multicolumn{2}{|c|}{ Girls } \\
\hline & Constancy index & Separation index & Constancy index & Separation index \\
\hline Height & $0.98(0.004)$ & $0.81(0.04)$ & $0.97(0.010)$ & $0.85(0.03)$ \\
\hline Weight & $0.94(0.011)$ & $0.80(0.04)$ & $0.95(0.012)$ & $0.83(0.03)$ \\
\hline Skinfold & $0.71(0 \cdot 060)$ & $0.55(0.07)$ & $0.78(0.045)$ & $0.56(0.06)$ \\
\hline
\end{tabular}

\section{Discussion}

The two indices presented here measure two different aspects of growth patterns. Their usefulness will become apparent as they are applied to growth data, especially in identifying the characteristics of individuals with particularly large or small values, and in comparing average values for groups. In practice they will be used to compare individuals and groups rather than one measurement with another.

It should be noted that the constancy index summarizes the overall variation and does not distinguish particular patterns. Thus, an individual who varies about a given percentile may obtain the same constancy value as one who moves steadily across the percentiles. The separation index, as expected, shows that the curves of individuals lying at the extremes are less likely to cross the curves of other individuals. In fact, for height the correlation between the standardized separation index and the absolute value of the individual's (standardized) mean is $0 \cdot 69$, and for the constancy index this correlation is -0.04 . The corresponding values for weight are 0.46 and -0.23 and for skinfold 0.79 and -0.35 . Thus, for weight and skinfold there is a small negative correlation between constancy and distance from the population mean, whereas, with a higher correlation, the separation index increases with increasing distance from the population mean. In judging the 'typicality' of an individual using either index, we may therefore obtain greater precision by taking account of the absolute value of the individual's (standardized) mean, and population norms of the conditional type could be constructed. 


\section{References}

Foulkes, M.A., and Davies, C.E., 1981, An index of tracking for longitudinal data. Biometrics (in the press). Goldstein, H., 1979, The Design and Analysis of Longitudinal Studies (London: Academic Press).

GoldsteIn, H., 1981, Some graphical procedures for the preliminary processing of longitudinal data. In Interpreting Multivariate Data, edited by V. Barnett (Chichester, New York: Wiley).

MCMahan, C. A., 1981, An index of tracking. Biometrics (in the press).

Miller, R. G., 1974, The jacknife- A review. Biometrika, 61, 1-15.

TANner, J. M., Whitehouse, R. H., and TAKaISHI, M., 1966, Standards from birth to maturity for height velocity and weight velocity: British Children 1965, II. Archives of Disease in Childhood, 41, 613-635.

Address correspondence to: Professor H. Goldstein, Department of Statistics and Computing, University of London Institute of Education, 20 Bedford Way, London WCIH OAL.

Zusammenfassung. Zwei Stabilitätsmaße auf der Grundlage von Längsschnitt-Wachstumsdaten werden beschrieben. Das erste, bezeichnet als Wachstums-Konstanz-Index, basiert auf der Variation der (standardisierten) Messung eines jeden Individuums um seinen Durchschnitt. Das andere, Wachstums-TrennungsIndex genannt, mißt das Ausmaß, in dem individuelle Wachstumskurven einander ïberkreuzen. Die Anwendungen dieser Indices werden beschrieben und Berechnungsformeln einschließlich der für den Standardfehler werden gegeben. Sie werden auf ein Beispiel mit Gruppenvergleichen von Daten der Körperhöhe des Gewichts und der Hautschichtdicke angewandt.

Resume. Deux mesures de stabilite basees sur des données de croissance longitudinales sont decrites. L'une, dénommée un indice de constance de croissance, est basée sur la variation de la mensuration (standardisée) de chaque individu par rapport à sa propre moyenne. L'autre, appelée un indice de séparation de croissance, mesure combien les courbes de croissance individuelles s'entrecroisent. L'utilisation de ces indices est décrite et des formules pour les calculer ainsi que leurs erreurs-types sont données. Elles sont appliquées à un exemple concernant des comparaisons de groupes de données sur la taille. le poids et les plis cutanés. 